\title{
Measurement of standard and off- axis elastic moduli and Poisson's ratios of spruce and yew wood in the transverse plane
}

\author{
Journal Article \\ Author(s): \\ Garab, Jozsef; Keunecke, Daniel; Hering, Stefan; Szalai, Jozsef; Niemz, Peter \\ Publication date: \\ 2010-08 \\ Permanent link: \\ https://doi.org/10.3929/ethz-b-000156377 \\ Rights / license: \\ In Copyright - Non-Commercial Use Permitted \\ Originally published in: \\ Wood Science and Technology 44(3), https://doi.org/10.1007/s00226-010-0362-2
}




\title{
Measurement of standard and off-axis elastic moduli and Poisson's ratios of spruce and yew wood in the transverse plane
}

\author{
Jozsef Garab • Daniel Keunecke • Stefan Hering • \\ Jozsef Szalai $\cdot$ Peter Niemz
}

Received: 9 March 2010/Published online: 11 July 2010

(C) Springer-Verlag 2010

\begin{abstract}
It is well known that in the radial-tangential plane of softwoods, the elastic modulus in the principal directions is clearly higher than the off-axis elastic moduli, which decrease to a minimum at a growth ring angle $\alpha$ of about $45^{\circ}$. However, this angular dependency was experimentally proven by only a few early publications. The aims of this study were (1) to analyze this relationship with up-todate equipment in compression tests on miniature softwood specimens with varying growth ring angles and (2) to compare the experimental results with those calculated by a tensor transformation to assess whether it is admissible to treat the investigated wood species as orthotropic materials. Two softwoods with distinctly different anatomic structures (Norway spruce and common yew) were chosen, and further properties such as Poisson's ratios were determined. The results confirm the abovementioned angle-dependent tendency for spruce elasticity, but also show that it is not valid for softwoods in general since the behavior of yew was completely different. The tissue textures of both species, particularly density and density distribution, were discussed as possible reason for these observed differences. The determined Poisson's ratios for principal and off-axis load directions may be useful for modeling of material behavior.
\end{abstract}

This article is dedicated to Gerd Wegener on the occasion of his retirement as professor at the Technische Universität München.

J. Garab · J. Szalai

Faculty of Wood Sciences, Institute for Applied Mechanics and Structures,

University of West Hungary, 9400 Sopron, Hungary

D. Keunecke $(\bowtie) \cdot$ S. Hering $\cdot$ P. Niemz

Institute for Building Materials (Wood Physics), ETH Zurich, 8093 Zurich, Switzerland

e-mail: danielk@ethz.ch 


\section{Introduction}

Numerous experimental investigations on wood mechanics are focused on determining elastic and strength properties. However, although being an orthotropic material, experiments on longitudinal (L) properties by far outnumber those on other principal directions. This certainly is due to the fact that $\mathrm{L}$ is the preferential direction in structural design since strength and stiffness properties are about one order of magnitude higher than transverse to the grain. Moreover, effort and difficulties to prepare and test specimens with alignment parallel to the grain are significantly reduced compared to other directions. Consequently, clearly more references are available from literature for the longitudinal modulus of elasticity (MOE) and strength, but also for the shear strength and moduli in the longitudinalradial (LR) and longitudinal-tangential (LT) planes, than for the parameters perpendicular to the grain or of the radial-tangential (RT) plane. Some of the exceptions are e.g., Hörig (1933), Krabbe (1960), Wommelsdorf (1966), Neuhaus (1981) and Bodig and Jayne (1993). However, the RT plane is a matter of particular interest since a transverse load is accepted and even intended in certain panel products (e.g., plywood, particle boards).

While the grain angle dependencies were the focus of diverse studies (e.g., Hearmon and Barkas 1941; Suzuki and Sasaki 1990; Kabir et al. 1997; Holmberg 2000; Liu 2002; Reiterer and Stanzl-Tschegg 2001; Yoshihara 2009), information on the angle-dependent elastic behavior within the RT plane is rather scarce for softwoods [for hardwoods, grain and ring angle-dependent compression tests were carried out by Lang et al. (2002)]. One reason for this could be that preparation of specimens with orthotropic mechanical properties might be hampered due to the influence of the growth ring curvature. Indeed, the elastic moduli along the principal directions $\mathrm{R}$ and $\mathrm{T}$ and the Poisson's ratios $v_{\mathrm{RT}}$ and $v_{\mathrm{TR}}$ are relatively well known for several wood species. However, the lateral contractions or extensions for load directions deviating from the principal directions (to simplify matters, also referred to as "Poisson's ratios" in the following) are completely unknown, and only few MOE values have been published for these directions. Their determination, in fact, is complicated. If determined experimentally, a dynamic method is commonly used: the measurement of ultrasound velocities (see for example Bucur and Archer (1984)) allows estimating MOE. Typically cubic or other polygonal specimens have to be prepared such that the ultrasound propagation direction is in accordance with the respective direction between the $\mathrm{R}$ and $\mathrm{T}$ axes. Preparing specimens for static tests following the same principle (where specimens are shaped such that uniaxial tests can be performed along the $\mathrm{R}$ and $\mathrm{T}$ axes and along directions between them) are possible but are scarce in literature. Some of the few exceptions are Jenkin (1920), Hearmon (1948) or Kennedy (1968).

Another possibility is a theoretical approach using tensor transformations according to Bodig and Jayne (1993; on the basis of Hörig (1933) and Voigt (1928)). To use this approach for all imaginable load directions, a complete set of 12 engineering elastic parameters (three Young's moduli $E$, six Poisson's ratios $v$, three shear moduli $G$ ) is required to fill the compliance matrix. These can be determined statically or as a combination of static and dynamic values. The elastic properties for 
material directions deviating from the principal directions can then be calculated. According to Bodig and Jayne (1993), such tensor transformations usually lead to results in the principal planes that are in satisfactory accordance with the "true" values.

In a previous study (Keunecke et al. 2008), this approach was used to estimate the off-axis compliance of two gymnosperm species (Norway spruce and common yew). For the three principal planes, the results were visualized in polar diagrams (Fig. 1). In the LR and LT planes, they only showed a slight divergence between both species. The general course of the curves was similar but at a different scale. In the RT plane, however, the curves completely differed. Here, the deformation of spruce was highly anisotropic: Even small deviations from the principal axes caused a considerable increase in compliance. The maximum value was reached at an angle $\alpha$ of about $40^{\circ}-50^{\circ}$ as a result of a small shear modulus $G_{R T}$. These findings agree with the relationship for the growth ring angle (GRA) of spruce that is often described in literature (e.g., Hörig 1933; Grimsel 1999): within the RT plane, the MOE of spruce is smallest at an angle $\alpha$ of about $45^{\circ}$ between both axes, resulting in the largest compliance in this direction. Yew behaved completely different: the deformation was largest on the $\mathrm{T}$ and $\mathrm{R}$ axes and slightly decreased to a minimum near $\alpha=45^{\circ}$. The lower directional dependence in the case of yew was ascribed to the small density variations between earlywood (EW) and latewood (LW) compared to spruce (cf. Keunecke et al. 2009): the LW densities of both species are similar, while the EW density is roughly twice as high in yew compared to spruce, resulting in a clearly less heterogeneous tissue composition in the RT plane, where EW bands are not that pronounced planes of weakness as in spruce.

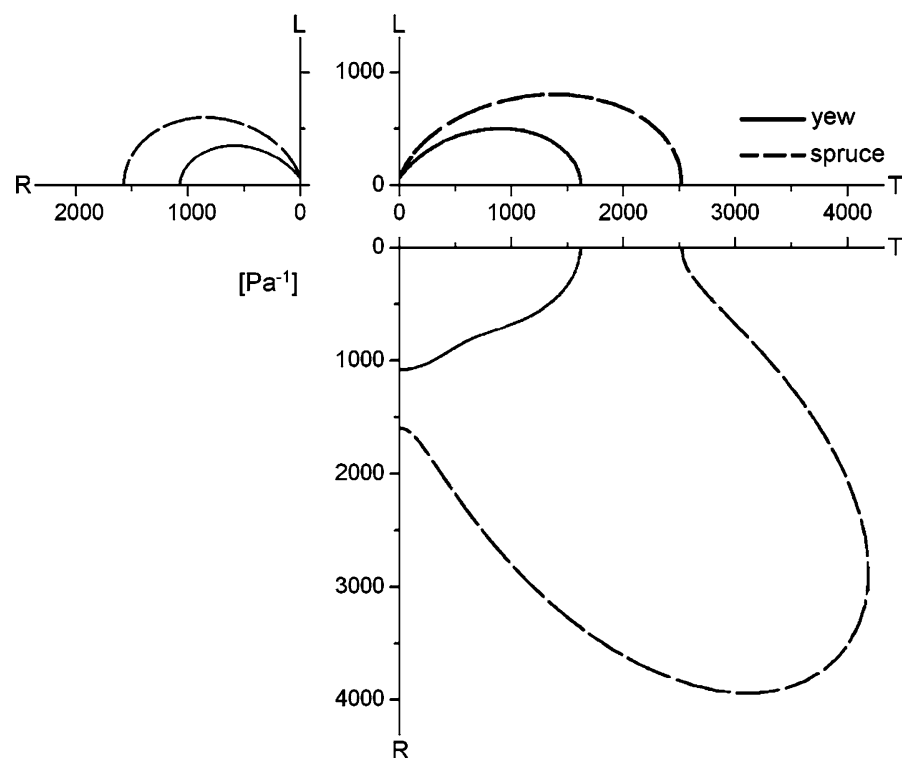

Fig. 1 Load-directional dependence of spruce and yew compliance illustrated in three polar diagrams (Keunecke et al. 2008) 
The drawback of a previous approach, however, was that dynamic and static methods were combined: dynamic methods to determine the shear moduli, and static tests to determine MOEs and Poisson's ratios. The present study continues on the previous one; with all mentioned aspects considered, the main goals of this study were thus

- to experimentally determine MOE values in $\mathrm{R}$ and $\mathrm{T}$ direction, and for several off-axis angles between $\mathrm{R}$ and $\mathrm{T}$ (with $\mathrm{L}$ always being perpendicular to the load direction), for Norway spruce and common yew in a static test with contemporary testing equipment. To choose yew wood in addition to spruce can provide interesting information about structure-property relationships as the microstructural properties of both species clearly differ (the air-dry density of yew is typically between 35 and $50 \%$ higher). This way, the findings of the previous study could be validated.

- to also determine Poisson's ratios for the same load axes as mentioned earlier for these species. So far, such data are also not available from literature.

- to evaluate the suitability of a mechanical approach to predict off-axis elastic moduli and Poisson's ratios in the RT plane.

\section{Materials and methods}

Miniature specimens from spruce (Picea abies [L.] Karst.) and yew (Taxus baccata L.) wood were produced and tested with a microcompression stage. The compression test was chosen to avoid the problematic influence of end constraints that typically accompany tensile tests. For strain measurement, digital image correlation (DIC) and the linear variable differential transformer (LVDT) of the compression stage were used.

\section{Specimens}

The raw material for specimen preparation was cut from five stems per species (at breast height) grown at stands close to Zurich, Switzerland. The spruce diameters in breast height were between 40 and $50 \mathrm{~cm}$, the yew diameters between 25 and $30 \mathrm{~cm}$. The boards for specimen preparation were gradually dried from the wet state to a wood moisture content of about $12 \%$. The samples were taken from the outer heartwood region where the anatomic structure is approximately orthotropic. This was the case for the spruce growth ring numbers 70-100 and the yew growth ring numbers 110-130. Samples containing compression wood, knots and other defects were omitted. The growth ring widths of the samples of both species were roughly equal.

For each species, 13 slats with a cross section of $30 \mathrm{~mm} \times 30 \mathrm{~mm}$ were planed. Then seven adjacent disks (each $4 \mathrm{~mm}$ thick) were cut out of each slat. Finally, specimens with cross-sectional dimensions of $10 \mathrm{~mm} \times 10 \mathrm{~mm}$ (in the radialtangential plane) and a thickness of $4 \mathrm{~mm}$ in the longitudinal direction were cut out of the disks, with the orientation of the GRA $\alpha$ in the RT plane being rotated in $15^{\circ}$ 
steps from specimen to specimen $\left(\alpha=\left\{0^{\circ}, 15^{\circ}, 30^{\circ}, 45^{\circ}, 60^{\circ}, 75^{\circ}, 90^{\circ}\right\}\right)$. In the following, $\alpha=" 0^{\circ}$ " is used synonymously to the radial and $\alpha=" 90^{\circ} "$ to the tangential direction. This means that a total of 182 specimens were tested. The preparation steps and load directions are illustrated in Fig. 2.

The density of the specimens varied from 0.38 to $0.53 \mathrm{~g} / \mathrm{cm}^{3}$ for spruce and from 0.51 to $0.82 \mathrm{~g} / \mathrm{cm}^{3}$ for yew wood. Since the Poisson's ratios had to be determined with DIC, a high-contrast speckle pattern was sprayed on one of the $10 \mathrm{~mm} \times 10 \mathrm{~mm}$ surfaces using an airbrush gun and finely pigmented acrylic paint. For further details, see Keunecke et al. (2008). Such patterns were necessary for the measurement of displacements on the specimen's surface during compression testing by means of DIC. The specimens were then stored in a climatic chamber at $20^{\circ} \mathrm{C}$ and $65 \%$ relative humidity.

\section{Compression experiments}

After the specimens reached equilibrium moisture content (spruce: 12\%; yew: $11-12 \%$ ), the compression tests were carried out using a micro stage (Deben, UK) with a load cell maximum capacity of $300 \mathrm{~N}$. Within the scope of this study, only the linear-elastic range between the end of the upward curvilinear tendency at the beginning of the stress-strain curves and about 30 to $40 \%$ of the first macro failure event was analyzed. At low stress levels, Hookean behavior can be assumed for wood. Therefore, the specimens were not loaded until failure, but the loading rate was chosen such that the first macrofailure of the specimens would have been reached within $90 \pm 30 \mathrm{~s}$. This was determined in preliminary tests and applied to different loading rates: for $\alpha=\left\{0^{\circ}, 15^{\circ}, 75^{\circ}, 90^{\circ}\right\}$ orientations of spruce wood and for all orientations of yew wood, a rate of $0.2 \mathrm{~mm} \mathrm{~min}^{-1}$ was chosen, and for the

(a)
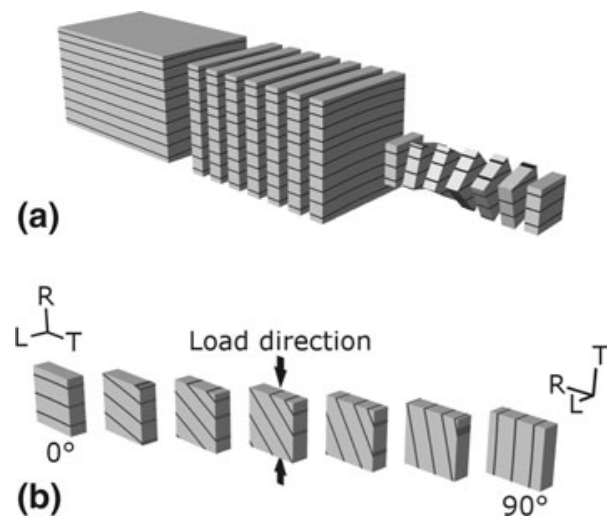

Fig. 2 Specimen preparation and orientation. a First, slats with a cross section of $30 \mathrm{~mm} \times 30 \mathrm{~mm}$ were planed, then seven disks (each $4 \mathrm{~mm}$ thick) were cut, and finally specimens with dimensions of $10 \mathrm{~mm} \times 10 \mathrm{~mm}$ (in the radial-tangential plane) were cut out of the disks, where the orientation in the RT-plane was rotated in $15^{\circ}$ steps from specimen to specimen. $\mathbf{b}$ Growth ring orientation in the specimens and load direction. $0^{\circ}$ corresponds to the radial load direction, $90^{\circ}$ to the tangential one 
remaining orientations of spruce wood a rate of $0.5 \mathrm{~mm} \mathrm{~min}^{-1}$. To reduce the frictional restraint at the loading platens of the testing machine, Teflon sheets were placed between the specimen and the platens. Otherwise, the specimen developed a bulged shape because the specimen ends were forced to have the same lateral deformation as the rigid metal platens (cf. van Mier 1997), thus causing artifacts when Poisson's ratios are determined.

Strain was measured in two ways: by means of LVDT of the testing stage and by VIC 2D (Correlated Solutions), a video image correlation system. In contrast to other locally measuring strain gauges, the VIC method allows full-field surface tracking of the in-plane sample deformations and computing 2-dimensional strain distribution based on gray value cross-correlations of the speckle pattern recorded via a CCD camera. Thus, during the compression tests, the specimen surface $(10 \mathrm{~mm} \times 10 \mathrm{~mm})$ was filmed with a resolution of about $950 \times 950$ pixels at a capture frequency of $4 \mathrm{~Hz}$. After computing the 2-dimensional strain, the average strain in the load direction and transverse to it was calculated.

Preliminary tests showed a very good correlation between both methods. For simplicity reasons, MOE was calculated using the LVDT values while Poisson's ratios were calculated based on VIC 2D measurements.

Calculation of Young's moduli and Poisson's ratios

The $\operatorname{MOE}(E)$ is the ratio of stress $(\sigma)$ to corresponding strain $(\varepsilon)$ when the material behaves elastically (Eq. 1). It is determined from the slope of the initial straight segment of the stress-strain diagram:

$$
E=\frac{\Delta \sigma}{\Delta \varepsilon}
$$

The phenomenon of lateral extension of a specimen occurring as it is being compressed is called Poisson's effect. The ratio of passive (=lateral extension) to active (=compression) strain is defined as Poisson's ratio $v_{k m}$ (Eq. 2):

$$
v_{k m}=\frac{-\varepsilon_{k}}{\varepsilon_{m}}
$$

where $k$ refers to the direction of lateral extension, and $m$ to load-directional compression.

Theoretical aspects of tensor transformation to predict Young's moduli and Poisson's ratios

Considering the tensor theory and orthotropic symmetries, it is possible to describe the elastic material behavior completely. With the knowledge of the material parameters in the principal planes, the elastic characteristics in every arbitrary direction can be predicted by a tensor transformation (Voigt 1928; Hörig 1933). Depending on the appropriate plane, the rotated main compliances $\tilde{s}_{i i}$ can be expressed as (Bodig and Jayne 1993) 


$$
\tilde{s}_{i i}=\frac{1}{E_{i j}^{k(\alpha)}}=\frac{1}{E_{i}} \cos ^{4}(\alpha)+\left(\frac{1}{G_{i j}}-\frac{2 v_{i j}}{E_{i}}\right) \sin ^{2}(\alpha) \cos ^{2}(\alpha)+\frac{1}{E_{j}} \sin ^{4}(\alpha)
$$

with $i, j=\mathrm{L}, \mathrm{R}$ or $\mathrm{L}, \mathrm{T}$ or $\mathrm{R}, \mathrm{T}$, and $\alpha$ is the grain angle or GRA. To calculate the angle-dependent moduli $E_{i j}^{k(\alpha)}$, at least three parameters are needed. Since the shear moduli were not determined in this study, another approach was used to predict the elastic moduli between the principal axes. Introducing the component $s_{i i j j}$ as

$$
s_{i i j j}=\frac{v_{j i}}{E_{j}}=\frac{1}{2}\left(\frac{4}{E_{i j}^{k(45)}}-\frac{1}{E_{i}}-\frac{1}{E_{j}}-\frac{1}{G_{i j}}\right)
$$

the unknown shear moduli can be substituted by the $\alpha=45^{\circ}$ Young's modulus (Szalai 1994). Hence, Eq. 3 can be rewritten as

$$
\frac{1}{E_{i j}^{k(\alpha)}}=\frac{1}{E_{i}} \cos ^{4}(\alpha)+\left(\frac{4}{E_{i j}^{k(45)}}-\frac{1}{E_{i}}-\frac{1}{E_{j}}\right) \sin ^{2}(\alpha) \cos ^{2}(\alpha)+\frac{1}{E_{j}} \sin ^{4}(\alpha)
$$

considering the anatomic directions of the investigated material. Continuing the previously used approach, the Poisson's ratios can be predicted as follows:

$$
-\frac{v_{i j}^{k(\alpha)}}{E_{i j}^{k(\pi / 2+\alpha)}}=-\frac{v_{i j}^{k(\alpha)}}{E_{i j}^{k(\alpha)}}=\left[\frac{1}{E_{i}}+\frac{1}{E_{j}}+\left(\frac{2 v_{i j}}{E_{j}}-\frac{1}{G_{i j}}\right)\right] \sin ^{2}(\alpha) \cos ^{2}(\alpha)-\frac{v_{i j}}{E_{i}}
$$

Substituting the term in parenthesis by $E_{i j}^{k(45)}$ leads to

$$
v_{i j}^{k(\alpha)}=-E_{i j}^{k(\alpha)}\left[\left[\frac{2}{E_{i}}+\frac{2}{E_{j}}-\frac{4}{E_{i j}^{k(45)}}\right] \sin ^{2}(\alpha) \cos ^{2}(\alpha)-\frac{v_{i j}}{E_{i}}\right]
$$

\section{Results and discussion}

Table 1 gives an overview of the MOE values and Poisson's ratios determined in the compression experiments. Compared to literature references (e.g., Bodig and Jayne 1993; Sell 1997; Wagenführ 2000), the MOE values here are quite low for both tested species. Since the load cell and LVDT of the micro stage were fully functional and worked precisely, this observed behavior must be inherent to the material. In the particular case, here, the size effect must have had an impact on the mechanical behavior and maybe also the length-to-width ratio of the specimens. However, as the basic conditions were the same for all specimens during testing, the results nevertheless allow for a comparison between both species.

\section{MOE}

The maxima of both species occur in the radial direction; this is a well-known relationship and is probably due to several reasons: 
Table 1 Experimentally determined parameters. 13 specimens per growth ring angle were tested for each species

\begin{tabular}{|c|c|c|c|c|c|c|c|c|}
\hline & & \multicolumn{7}{|c|}{ Growth ring angle $\alpha\left(^{\circ}\right)$} \\
\hline & & 0 & 15 & 30 & 45 & 60 & 75 & 90 \\
\hline \multicolumn{9}{|l|}{ Spruce } \\
\hline \multirow[t]{2}{*}{ Density $\rho\left(\mathrm{g} \mathrm{cm}^{-3}\right)$} & $\bar{x}$ & 0.46 & 0.46 & 0.46 & 0.45 & 0.46 & 0.45 & 0.46 \\
\hline & $\mathrm{CoV}$ & 0.09 & 0.11 & 0.1 & 0.1 & 0.1 & 0.1 & 0.1 \\
\hline \multirow[t]{2}{*}{ MOE $E(\mathrm{MPa})$} & $\bar{x}$ & 211 & 156 & 100 & 95 & 114 & 160 & 194 \\
\hline & $\mathrm{CoV}$ & 0.12 & 0.19 & 0.17 & 0.19 & 0.12 & 0.22 & 0.11 \\
\hline \multirow[t]{2}{*}{ Poisson's ratios $v(-)$} & $\bar{x}$ & 0.59 & 0.83 & 0.89 & 0.91 & 0.87 & 0.64 & 0.31 \\
\hline & $\mathrm{CoV}$ & 0.12 & 0.09 & 0.07 & 0.06 & 0.07 & 0.19 & 0.17 \\
\hline \multicolumn{9}{|l|}{ Yew } \\
\hline \multirow[t]{2}{*}{ Density $\rho\left(\mathrm{g} \mathrm{cm}^{-3}\right)$} & $\bar{x}$ & 0.63 & 0.62 & 0.63 & 0.62 & 0.63 & 0.63 & 0.63 \\
\hline & $\mathrm{CoV}$ & 0.16 & 0.16 & 0.15 & 0.16 & 0.15 & 0.16 & 0.16 \\
\hline \multirow[t]{2}{*}{ MOE $E(\mathrm{MPa})$} & $\bar{x}$ & 237 & 216 & 221 & 206 & 204 & 211 & 207 \\
\hline & $\mathrm{CoV}$ & 0.24 & 0.19 & 0.16 & 0.29 & 0.29 & 0.33 & 0.19 \\
\hline \multirow[t]{2}{*}{ Poisson's ratios $v(-)$} & $\bar{x}$ & 0.79 & 0.77 & 0.83 & 0.78 & 0.66 & 0.52 & 0.48 \\
\hline & $\mathrm{CoV}$ & 0.18 & 0.11 & 0.15 & 0.09 & 0.13 & 0.14 & 0.17 \\
\hline
\end{tabular}

The statistical spread of the values is visualized in Figs. 2 and 3. $\bar{x}=$ arithmetic mean; CoV $=$ coefficient of variation. $\alpha=0^{\circ}$ corresponds to the radial and $\alpha=90^{\circ}$ to tangential load direction

- The sandwich-like composition of EW and LW cells leads to the expectation of higher tangential moduli, since the weakness in this direction of the EW layer is not that pronounced, but due to their reinforcing effect, wood rays overcompensate this weakness (cf. Burgert (2000) and others).

- Further causes can be sought in the strict structural alignment of tracheids in the radial direction and the transverse anisotropy at the cell wall level.

While 50\% higher values are often reported for the radial compared to the tangential direction (e.g., Niemz 1993; Sell 1997; Forest Products Laboratory 2000), in this present study the spruce values were $9 \%$ higher in the radial direction and the yew values $14 \%$ (probably due to the higher ray percentage of yew compared to spruce). These findings were confirmed by DIC strain measurement. The basis of the obvious differences to the literature references is open to speculation. It is conceivable that these findings result from the sample geometry: while MOE values are in most cases determined on bar-shaped specimens, the geometry of the samples of this study resembles more a panel. But also the size effect might play an important role: values stated in literature are based on larger specimens than the ones of this study, and the probability of a slight growth ring curvature in the tangential direction is higher in larger specimens than in smaller ones. Consequently, this can lead to underestimated tangential MOE values in larger specimens, since even a small deviation from the straight tangential alignment of growth rings can clearly affect the elastic behavior as shown in Fig. 1. 
Spruce showed strong anisotropy with a maximum mean at $\alpha=0^{\circ}$ $\left(\bar{E}^{(0)}=211 \mathrm{MPa}\right)$ and a strong decrease to $\bar{E}^{(45)}=95 \mathrm{MPa}$. The yew mean values were higher (between $\bar{E}^{(60)}=204$ and $\bar{E}^{(0)}=237 \mathrm{MPa}$ ); in view of the $35-40 \%$ higher density of the yew samples, even higher yew values are possible. The range between minima and maxima was clearly smaller compared to spruce, indicating the lower degree of transverse anisotropy. This is due to the more regular tissue composition of yew: on the one hand, its cell cross sections often appear rather circular or elliptical than rectangular. On the other hand in the radial direction, where wood can be considered as a sandwich construction with alternating layers, the density differences between EW and LW are clearly smaller than in spruce. This was exemplary shown in a previous study (Keunecke et al. 2009) on two random samples of both species: similar LW density maxima were measured for spruce and yew; the EW minima of yew, however, were about two-fold higher compared to spruce.

Thus, the EW zones of spruce are more pronounced planes of weakness than the relatively compact EW zones of yew. This was confirmed by the DIC evaluation revealing clearly larger differences between load-directional strain of EW and LW in spruce than in yew: Figure 3 shows a clear separation between EW and LW zones of spruce. However, this separation is not visible for the tangential load direction $\left(\alpha=90^{\circ}\right)$. For yew, this separation was less clear and (if at all) only possible for the off-axis load directions $\left(\alpha=\left\{15^{\circ}, 30^{\circ}, 45^{\circ}, 60^{\circ}, 75^{\circ}\right\}\right)$.

Furthermore, yew is characterized by a high ray percentage [about $14 \%$, compared to 4-6\% in spruce (Wagenführ 2000)]. And as $G_{R T}$ is strongly influenced by density and by the presence and arrangement of wood rays, the ratios $G_{R T} / E_{R}$ and $\mathrm{G}_{\mathrm{RT}} / \mathrm{E}_{\mathrm{T}}$ are smaller for spruce (cf. Keunecke et al. 2008). This is reflected in the offaxis MOE values in the transverse planes, since shear stresses are additionally generated in orthotropic materials when the load axes deviate from the three principal axes. Thus, the shear coupling effect, particularly in spruce, increases from the principal material axes toward $\alpha=45^{\circ}$ accompanied by decreasing stiffness (cf. Shipsha and Berglund (2007) regarding the shear coupling effect).

While the influence of density and density distribution on the transverse elastic behavior is plausible, the microfibril angle of the S2 layer influences longitudinal but not transverse elasticity. This was illustrated for the fiber wall by Bergander and Salmén (2000). Altogether, the present values confirm the tendency which the previous study (Keunecke et al. 2008) revealed, namely elastic anisotropy with significant differences for both species.

\section{Experimental versus theoretical off-axis MOE}

The relationship between mean values from experiments and data calculated according to Eq. 5 is shown in Fig. 4 and compared with results of a previous study by the authors. They are displayed more commonly using compliance parameters. It has to be considered that the calculated data are based on the experimental parameters $E_{R}, E_{R T}^{L(45)}$ and $E_{T}$. Thus, only the deviations for the remaining angles can be considered to assess whether the agreement between both groups is good. In this 

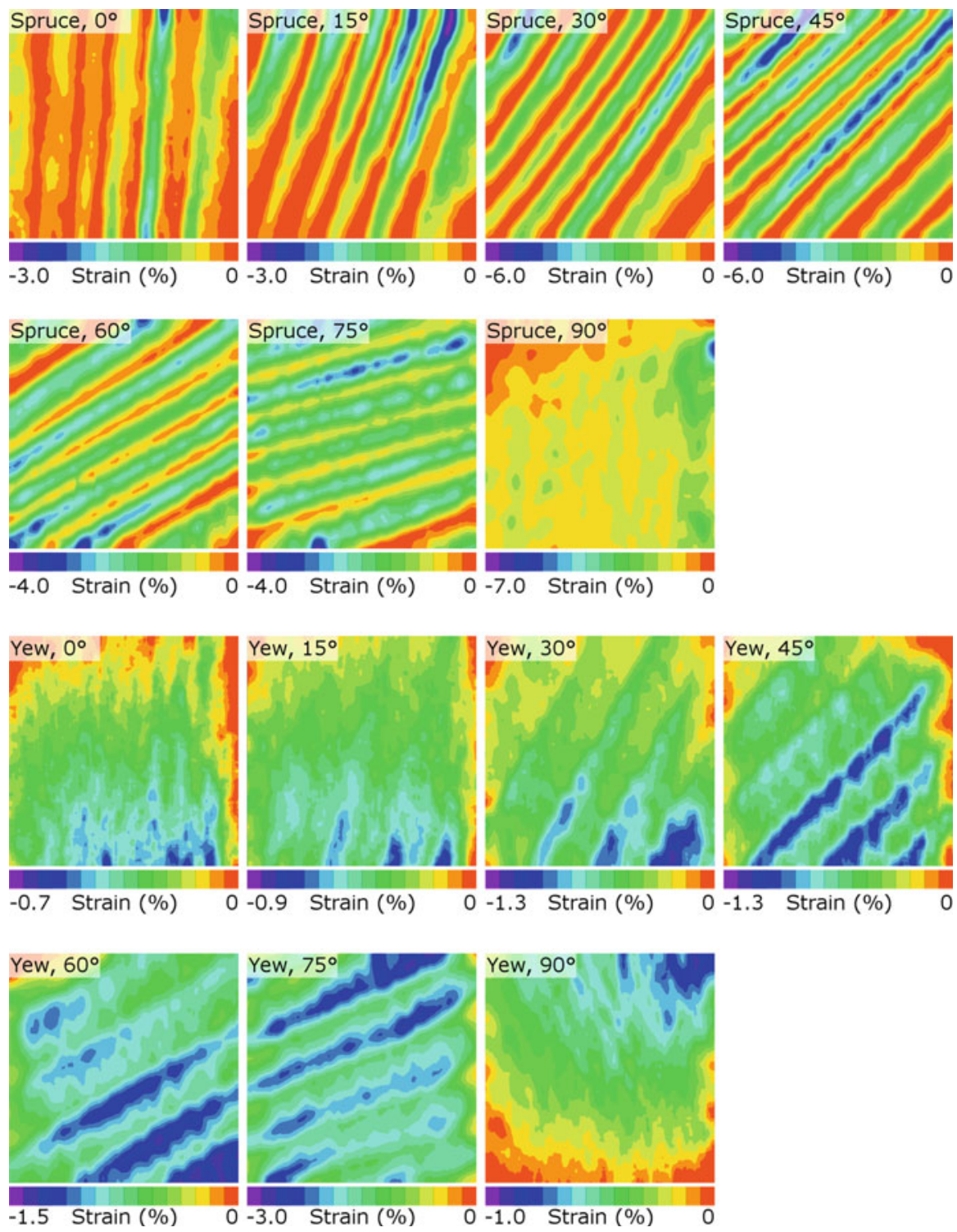

Fig. 3 Load-directional strain in spruce and yew samples dependant on the respective growth ring angle $\alpha$ (determined with DIC). The specimens were loaded in the horizontal direction, and this is also the visualized strain direction. The images show the strain situation at the end of the linear-elastic range, immediately before plastic deformation started

study, the congruence is indeed high. The good correlation between experimental and theoretical results indicates that both species can be fairly considered as orthotropic materials. 


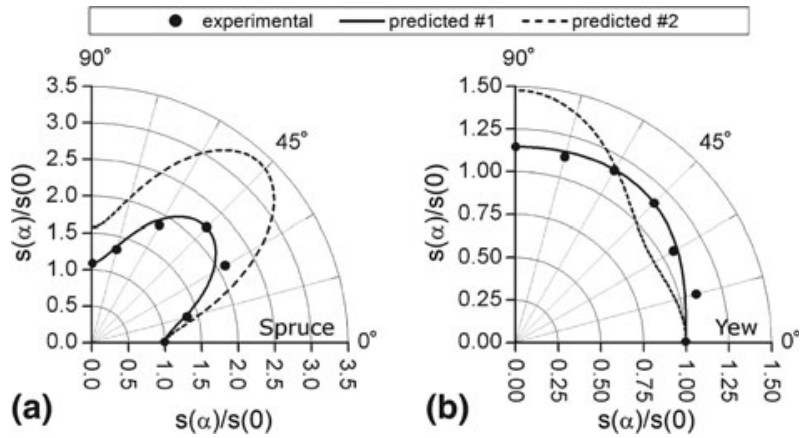

Fig. 4 Comparison between experimentally and theoretically determined compliances $s$ of a spruce and b yew wood depending on the growth ring angle. The compliances are normalized with $\mathrm{s}(\alpha) / \mathrm{s}(0)=1$ for a growth ring angle $\alpha=0^{\circ}$ corresponding to the radial load direction. predicted \#1 corresponds to Eq. 5, and predicted \#2 (cf. Fig. 1) represents the results of a previous study (Keunecke et al. 2008)

The general characteristics of the curves regarding the differences between both species correspond to the results of the previous study. The curves of the previous study, however, are slightly displaced to the tangential direction.

\section{Poisson's ratios}

The Poisson's ratios for spruce in the principal axes (mean value at $\left.\alpha=0^{\circ}=\bar{v}^{(0)}=0.59 ; \bar{v}^{(90)}=0.31\right)$ are in good agreement with values published by other authors (Hörig 1933; Wommelsdorff 1966; Neuhaus 1981) and with own measurements (Keunecke et al. 2008). The spruce maxima were $\bar{v}^{(30)}=0.89$ and $\bar{v}^{(45)}=0.91$, with a decreasing tendency toward the $\mathrm{R}$ and $\mathrm{T}$ axes and the minimum for $\bar{v}^{(90)}=0.31$. The range for the yew mean values was relatively small for $\alpha=\left\{0^{\circ}, 15^{\circ}, 30^{\circ}, 45^{\circ}\right\}$ (from 0.77 to 0.83 ). From $\alpha=60^{\circ}$ to $90^{\circ}$, the values decreased (to $\bar{v}^{(90)}=0.48$ ). Apparently the differences between spruce and yew were a little less pronounced than for the elastic moduli (Fig. 5).

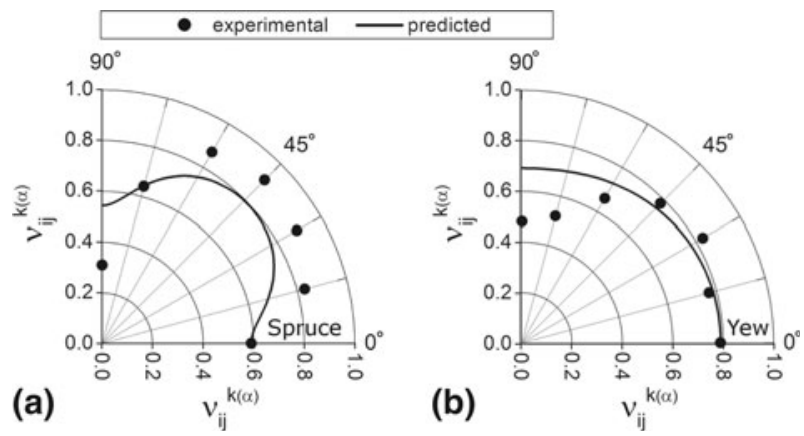

Fig. 5 Comparison between experimentally and theoretically determined Poisson's ratios $v_{i j}^{k(\alpha)}$ of spruce and yew wood, illustrated as a polar diagram. A growth ring angle $\alpha=0^{\circ}$ corresponds to the radial, $\alpha=90^{\circ}$ to the tangential load direction. $i$ refers to the load direction, and $j$ to the direction of lateral extension. The predicted curve was calculated according to Eq. 7 
Experimental versus theoretical Poisson's ratios

In principle, the compliance matrix should be symmetric in orthotropic materials, i.e.,

$$
\frac{v_{T R}}{E_{T}}=\frac{v_{R T}}{E_{R}}
$$

However, this was not the case in this study. Similar deviations were described by Bodig and Jayne (1983) and Neuhaus (1983). Several reasons are possible for this:

- Wood is considered to show linear elastic orthotropic material behavior. But as a natural material, this of course can only be an approximation, since the microscopic structure of softwoods can be rather irregular.

- The employed method allows for only an approximation of the "true" Poisson's ratios, since only the upper specimen surface was analyzed.

The experimental values $\bar{v}^{(15)}, \bar{v}^{(30)}, \bar{v}^{(45)}$ and $\bar{v}^{(60)}$ for spruce were significantly higher than the predicted values (Fig. 5). $\bar{v}^{(75)}$ agrees with the prediction, and $\bar{v}^{(90)}$ is the only value that is below the predicted one. In the case of yew, the Poisson ratios $\bar{v}^{(15)}, \bar{v}^{(30)}, \bar{v}^{(45)}$ and $\bar{v}^{(60)}$ are close to the prediction, while $\bar{v}^{(75)}$ and $\bar{v}^{(90)}$ are clearly lower. Here, the applicability of the predictive approach seems clearly limited. This is possibly due to the fact that the mechanical model is better suited for the macroscopic than for the mesoscopic behavior of softwoods.

\section{Conclusion}

The transverse compression test experimentally confirmed the principle tendencies for the off-axis MOE values of spruce in the RT plane estimated in some older publications on the basis of tensor transformations. In addition, it was demonstrated that this is not a general behavior of softwoods; yew wood showed a different behavior with a lower degree of anisotropy. The good agreement of the experimental results and the compliance values estimated in the previous study on the basis of tensor transformation shows that spruce and yew wood can be treated as orthotropic materials. Their elastic properties have to be explained in terms of differences in the wood texture between both species (structure-function relationships). In this regard, modeling approaches might provide a possibility to clarify the question how density and density distribution influence the elastic behavior in the RT plane, and whether they even can be the crucial factors. For an approximate MOE assessment for load directions deviating from the principal axes and the $\alpha=45^{\circ}$ direction, the chosen mechanical approach seems well suited, but less for the Poisson's ratios. The determined Poisson's ratios, particularly for the off-axis load directions, may be important elastic parameters for the modeling of material behavior, especially as the latter were not yet available for the transverse plane. 


\section{References}

Bergander A, Salmén L (2000) Variations in transverse fibre wall properties: relations between elastic properties and structure. Holzforschung 54:654-660

Bodig J, Jayne BA (1993) Mechanics of wood and wood composites. Krieger Publishing Company, Malabar

Bucur V, Archer RR (1984) Elastic constants for wood by an ultrasonic method. Wood Sci Technol 18:255-265

Burgert I (2000) Die mechanische Bedeutung der Holzstrahlen im lebenden Baum. Dissertation, University of Hamburg

Forest Products Laboratory (2000) Wood handbook—wood as an engineering material. University Press of the Pacific, Honolulu

Grimsel M (1999) Mechanisches Verhalten von Holz: Struktur- und Parameteridentifikation eines anisotropen Werkstoffes. Dissertation, Technische Universität Dresden

Hearmon RFS (1948) The elasticity of wood and plywood. DSIR, For Prod Special Rept No. 7. HMSO, London

Hearmon RFS, Barkas WW (1941) The effect of grain direction on the Young's moduli and rigidity moduli of beech and Sitka spruce. Proc Phys Soc 53:674-680

Holmberg H (2000) Influence of grain angle on Brinell hardness of Scots pine (Pinus sylvestris L.). Holz Roh Werkst 58:91-95

Hörig H (1933) Zur Elastizität des Fichtenholzes. 1. Folgerungen aus Messungen von H. Carrington an Spruce. Z Tech Phys 12:369-379

Jenkin CF (1920) Report on materials used in the construction of aircraft engines. London: HMSO (Her Majesty's Stationery Office)

Kabir MF, Sidek HAA, Daud WM, Khalid K (1997) Effect of moisture content and grain angle on the ultrasonic properties of rubber wood. Holzforschung 51:263-267

Kennedy RW (1968) Wood in transverse compression. For Prod J 18:36-40

Keunecke D, Hering S, Niemz P (2008) Three-dimensional elastic behaviour of common yew and Norway spruce. Wood Sci Technol 42:633-647

Keunecke D, Evans R, Niemz P (2009) Microstructural properties of common yew and Norway spruce determined with Silviscan. IAWA J 30:165-178

Krabbe E (1960) Messungen von Gleit- und Dehnungszahlen an Holzstabchen mit rechteckigen Querschnitten. Dissertation, Hannover, p 106

Lang EM, Bejo L, Szalai J, Kovacs Z, Anderson RB (2002) Orthotropic strength and elasticity of hardwoods in relation to composite manufacture. Part II. Orthotropy of compression strength and elasticity. Wood Fiber Sci 34:350-365

Liu JY (2002) Analysis of off-axis tension test of wood specimens. Wood Fiber Sci 34:205-211

Neuhaus FH (1981) Elastizitätszahlen von Fichtenholz in Abhängigkeit von der Holzfeuchtigkeit. Dissertation, University of Bochum

Neuhaus H (1983) Über das elastische Verhalten von Fichtenholz in Abhängigkeit von der Holzfeuchtigkeit. Holz Roh Werkst 41:21-25

Niemz P (1993) Physik des Holzes und der Holzwerkstoffe. DRW, Leinfelden-Echterdingen

Reiterer A, Stanzl-Tschegg SE (2001) Compressive behaviour of softwood under uniaxial loading at different orientations to the grain. Mech Mater 33:705-715

Sell J (1997) Eigenschaften und Kenngrössen von Holzarten. Baufachverlag, Dietikon

Shipsha A, Berglund LA (2007) Shear coupling effects on stress and strain distributions in wood subjected to transverse compression. Compos Sci Technol 67:1362-1369

Suzuki H, Sasaki E (1990) Effect of grain angle on the ultrasonic velocity of wood. Mokuzai Gakkaishi 36:103-107

Szalai J (1994) A faanyag és faalapú anyagok anizotrop rugalmasság- és szilárdságtana (English title: Anisotropic strength and elasticity of wood and wood based composites), Sopron [in Hungarian]

Van Mier JGM (1997) Fracture processes of concrete: assessment of material parameters for fracture models. CRC Press, Boca Raton

Voigt W (1928) Lehrbuch der Kristallphysik. B.G. Teubner, Leipzig

Wagenführ R (2000) Holzatlas. Fachbuchverlag Leipzig, Munich 
Wommelsdorff O (1966) Dehnungs- und Querdehnungszahlen von Hölzern. Dissertation, University of Hannover

Yoshihara H (2009) Prediction of the off-axis stress strain relation of wood under compression loading. Eur J Wood Prod 67:183-188 